\title{
EDUCAÇÃO FÍSICA E GESTÃO ESCOLAR: REFLEXÕES SOBRE LEGISLAÇÃO, PRODUÇÃO ACADÊMICA E FORMAÇÃO DOCENTE
}

\author{
Fernando Torres Otero de SOUZA ${ }^{i}$ \\ Rodrigo Lema Del Rio MARTINS ${ }^{\text {ii }}$
}

André da Silva MELLO ${ }^{\text {iii }}$

\begin{abstract}
RESUMO
O presente estudo trata da participação do professor de Educação Física (EF) na gestão escolar. Combinando pesquisa documental e bibliográfica, analisaram-se as orientações legais para formação de licenciados em EF, os currículos prescritos dos cursos de EF da Grande Vitória (GV), Espírito Santo, e a produção acadêmica da área no tocante à gestão escolar. Utilizou-se como fontes: Lei de Diretrizes e Bases da Educação Nacional (Lei No 9.394/1996), Resoluções do Conselho Nacional de Educação (CNE), No 7/2004, $\mathrm{N}^{\circ}$ 2/2015, $\mathrm{N}^{\circ}$ 6/2018 e $\mathrm{N}^{\circ}$ 2/2019, perfis dos egressos e matrizes de disciplinas dos cursos de licenciatura em EF da GV. A pesquisa bibliográfica foi realizada em oito periódicos e bancos de teses e dissertações dos cursos de Pós-Graduação stricto sensu em EF. O trabalho indicou que a gestão vem ganhando espaço na atuação profissional e orientações legais da EF. Entretanto, observou-se baixa produção acadêmica e pouca repercussão nos currículos dos cursos de formação da área, indicando divergência entre atuação/orientações e formação/produção.
\end{abstract}

PALAVRAS-CHAVE: Gestão escolar; Educação Física; Formação.

\section{PHYSICAL EDUCATION AND SCHOOL MANAGEMENT: REFLECTIONS ON LEGISLATION, ACADEMIC PRODUCTION AND TEACHER TRAINING}

\begin{abstract}
This study deals with the participation of Physical Education (PE) teacher in school management. Combining documentary and bibliographic research we analyzed the legal guidelines for the teaching degree in PE, the prescribed curricula of PE courses in Grande Vitória, Espirito Santo, Brazil, and the academic production in the area regarding school management. As sources we used: National Education Guidelines and Framework Law (no. 9.394/1996), Resolutions of the National Council of

\footnotetext{
${ }^{\text {i }}$ Mestrado em Educação Física pela Universidade Federal do Espírito Santo (UFES-2019). Professor efetivo da Rede Municipal de Vitória/ES, atuando como docente e diretor em unidades de Educação Infantil. Membro do Núcleo de Aprendizagens com as Infâncias e seus Fazeres (NAIF/UFES). E-mail: fernandootero2@hotmail.com.

ii Doutorado em Educação Física pela Universidade Federal do Espírito Santo (UFES-2018). Professor do curso de Educação Física da Universidade Federal do Tocantins (UFT). Líder do Núcleo de Aprendizagens com as Infâncias e seus Fazeres (NAIF/UFES) e do Grupo de Investigação Pedagógica em Educação Física (GIPEF/UFT). E-mail: rodrigodrmartins@uft.edu.br.

iii Doutorado em Educação Física pela Universidade Gama Filho (2007) e Pós-Doutorado pelo Programa Associado em Educação Física da UEM/UEL (2019). Professor do Programa de Pós-Graduação em Educação Física da UFES. Líder do Núcleo de Aprendizagens com as Infâncias e seus Fazeres (NAIF/UFES). E-mail: andremellovix@gmail.com.
}

Revista e-Curriculum, São Paulo, v.18, n.1, p. 327-349 jan./mar. 2020

Programa de Pós-graduação Educação: Currículo - PUC/SP

e-ISSN: $1809-3876$

http://revistas.pucsp.br/index.php/curriculum 
Education, no. 7/2004, no. 2/2015, no. 6/2018 and $n^{\circ} 2 / 2019$, undergraduates students' profiles and matrices of subjects of the PE courses in Grande Vitória. The bibliographic research was performed in eight journals and thesis and dissertation database of stricto sensu Post-Graduate courses in PE. The work indicated that management has been gaining ground in the professional performance and legal guidelines of PE. However, there was low academic production and little repercussion in the curricula of the area's training courses, indicating divergence between performancelorientation and training/production.

KEYWORDS: School management; Physical Education; Education.

\title{
EDUCACIÓN FÍSICA Y GESTIÓN ESCOLAR: REFLEXIONES SOBRE LEGISLACIÓN, PRODUCCIÓN ACADÉMICA Y FORMACIÓN DOCENTE
}

\begin{abstract}
RESUMEN
El presente estudio trata de la participación del profesor de Educación Física (EF) en la gestión escolar. Combinando investigación documental y bibliográfica, se analizaron las orientaciones legales para formación de licenciados en EF, los planes de estudios prescritos de los cursos de EF de Grande Vitória $(G V)$, Espírito Santo, Brasil, y la producción académica del área con respecto a la gestión escolar. Se utilizaron como fuentes: Ley de Directrices y Bases de la Educación Nacional $\left(N^{o}\right.$ 9.394/1996), Resoluciones del Consejo Nacional de Educación (CNE), $N^{o} 7 / 2004, N^{o}$ 02/2015, $N^{o}$ $6 / 2018$ y $N^{\circ} 2 / 2019$, perfiles de los titulados y matrices de las disciplinas de los cursos de licenciatura en EF de la GV. La investigación bibliográfica fue realizada en ocho periódicos y bases de datos de tesis y disertaciones de las carreras de posgrado stricto sensu en EF. El trabajo indicó que la gerencia ha ganado espacio en la actuación profesional y orientaciones legales de la EF. Sin embargo, se observó baja producción académica y poca repercusión en los planes de estudio de las carreras de formación del área, indicando divergencia entre actuación/orientaciones y la formación/producción.
\end{abstract}

PALABRAS CLAVE: Gestión escolar; Educación Física; Formación.

\section{INTRODUÇÃO}

O campo de atuação profissional para os licenciados em Educação Física (EF) não se restringe às atividades de sala de aula. De acordo com Larocca e Junges (2004), o exercício de outras atividades ou funções por parte dos professores, que extrapolam a dimensão pedagógica na regência de classe, configura-se como um fator importante na constituição da identidade docente.

Em consonância com essa perspectiva, a Resolução do Conselho Nacional de Educação (CES) N 6/2018, que trata das Diretrizes Curriculares Nacionais para os cursos de graduação em Educação Física (DCNEF), estabelece que: “A etapa específica para formação 
em Licenciatura deverá garantir nos currículos interdisciplinares [...] formação na área de políticas públicas e gestão da educação [...]” (BRASIL, 2018, p. 4).

Entre os papéis que o professor de EF pode desempenhar no âmbito da educação, neste artigo, destacamos a direção/gestão escolar, termos que assumiremos como sinônimos. Gerir uma unidade de ensino envolve elementos que influenciam o trabalho desenvolvido na/pela comunidade escolar e têm como eixos centrais as gestões de pessoas, pedagógica e administrativa, de forma democrática e participativa (LÜCK, 2009). Esses eixos, segundo a autora, exigem conhecimentos relacionados ao planejamento e à organização do trabalho escolar, à compreensão de fundamentos e aos princípios da educação e da gestão educacional, ao monitoramento de processos administrativos e financeiros, bem como à avaliação institucional e ao acompanhamento dos resultados educacionais.

Acerca dessa relação da atuação profissional de docentes com formação em EF com as atividades de gestão escolar, Noronha e Teixeira (2015) identificaram que

[...] diversos professores de Educação Física começaram a concorrer nos processos eleitorais, sendo eleitos e desempenhando o papel de diretores ou vice-diretores. Tal situação pode ser compreendida considerando-se não só as características pessoais de cada um deles, mas também competências e habilidades comuns aos professores e profissionais da área, como a liderança, o empreendedorismo, a capacidade de escuta, de desenvolver redes de relacionamentos que chegam às famílias e às comunidades atendidas pelas escolas, mediada pela vivência da corporalidade, de afetos e sentimentos (NORONHA; TEIXEIRA, 2015, p. 90).

Em 2017, constatamos na Rede Municipal de Ensino de Vitória/ES que, em um total de 4.481 docentes, $339(7,6 \%)$ eram professores de EF e que, de suas 101 unidades de ensino, onze delas elegeram docentes de EF para na função de diretor escolar, o que representava $10,9 \%$ do total.

O número crescente de professores de EF na gestão escolar, mais especificamente em Vitória/ES, instigou-nos a pensar sobre aspectos legais e pedagógicos que cercam a formação desses docentes e a produção de conhecimento na área. Nossas reflexões caminharam no sentido de indagar: $O$ que os documentos que orientam os cursos de formação inicial em Educação Física indicam sobre a gestão escolar? Como o campo acadêmico-científico da Educação Física tem abordado as questões relativas à participação de profissionais dessa área na gestão escolar? Quais são os saberes mobilizados nos currículos dos cursos de formação 
inicial em EF da Região Metropolitana da Grande Vitória/ES (GV) ${ }^{1}$ que subsidiem a atuação profissional para a gestão escolar?

Para respondermos a essas perguntas, este artigo objetiva analisar as orientações legais para a formação de professores, a produção acadêmico-científica da Educação Física sobre a gestão escolar e os currículos prescritos dos cursos de formação inicial em EF na GV.

\section{MÉTODO}

Para alcançar o objetivo proposto, combinamos a pesquisa documental com a pesquisa bibliográfica (LAKATOS; MARCONI, 2003). Os documentos utilizados neste estudo foram: a Lei de Diretrizes e Bases da Educação Nacional (Lei N ${ }^{\circ}$ 9.394/1996) e as Resoluções do Conselho Nacional de Educação (CNE) No 7/2004, No 2/2015, No 6/2018 e No 2/2019, os perfis dos egressos e as matrizes de disciplinas dos cursos de formação de professores de EF da GV. A pesquisa bibliográfica focalizou a produção acadêmico-científica da EF brasileira no tocante à gestão escolar, veiculada em artigos, dissertações e teses.

As fontes documentais permitiram-nos realizar um levantamento histórico das orientações curriculares de formação docente, tanto das licenciaturas em geral, quanto específica em EF, que foram selecionadas por mencionarem a gestão escolar em seus conteúdos. Os perfis de egressos e as matrizes de disciplinas foram incorporados ao debate, intencionando compreender a materialização das orientações legais na formação oferecidas pelas Instituições de Ensino Superior (IES).

Delimitamos a investigação às IES da região metropolitana de Vitória/ES, que oferecem o curso de licenciatura em EF na modalidade presencial, sendo elas: Universidade Federal do Espírito Santo (UFES), Católica Vitória Centro Universitário (Salesiano), Fabra, Faculdade Estácio de Sá, Faculdade Pitágoras, Universidade Vila Velha (UVV), Faculdade Multivix e Faculdade Doctum. Essa escolha deve-se ao seu impacto predominante na formação dos professores de EF que são diretores na Rede Municipal de Vitória/ES.

Realizamos buscas em periódicos científicos ${ }^{2}$ da área que possuem melhor classificação no WebQualis da Coordenação de Aperfeiçoamento de Pessoal de Nível Superior (Capes) $)^{3}$ (2013-2016) e nos repositórios disponíveis online de cada Programa de Pós-Graduação ${ }^{4}$ que possuem áreas de concentração e/ou linhas de pesquisas com as vertentes sociocultural e pedagógica, até julho de 2018. Em uma primeira fase da pesquisa, 
utilizamos os descritores: Gestão; Gestão Escolar; Gestão Educacional; Diretor escolar; Direção. Ao observarmos um número muito baixo de artigos, procedemos a uma investigação aprofundada, entrando em cada uma das edições das revistas selecionadas e em todos os arquivos disponibilizados pelos Programas investigados.

Nessa etapa do trabalho, somando-se as publicações em revistas e as dissertações e teses defendidas, foram visitadas 9.920 produções. Na seleção dos textos, realizamos a leitura dos títulos de todos os trabalhos. Quando observadas relações com o objeto deste estudo, procedemos à leitura dos resumos, e, quando ainda restavam dúvidas, procedíamos a leitura do trabalho na íntegra. Do total, encontramos dois artigos e quatro dissertações que mantiveram relação com a temática focalizada neste estudo.

\section{ANÁLISE DOCUMENTAL DA FORMAÇÃO DE PROFESSORES DE EF}

Para subsidiar a discussão que orienta a formação de professores no Brasil para atuação na Educação Básica, dialogamos com os seguintes documentos: Lei de Diretrizes e Bases da Educação Nacional (LDB - Lei N ${ }^{\circ}$ 9.394/1996); as Resoluções do CNE N 7/2004 e No 6/2018, que instituíram/instituem as DCNEF, e as Resoluções No 2/2015 e No 2/2019, que regulamentam a formação geral para todas as licenciaturas atualmente. Todos esses documentos estão sintetizados no Quadro 1, apresentado a seguir.

Quadro 1 - Síntese dos documentos legais que normatizam a formação docente no Brasil

\begin{tabular}{|c|c|}
\hline $\begin{array}{c}\text { Lei No } 9.394 \\
\text { (BRASIL, 1996) }\end{array}$ & $\begin{array}{l}\text { Art. 14. Os sistemas de ensino definirão as normas da gestão democrática do ensino } \\
\text { público na educação básica, de acordo com as suas peculiaridades e conforme os } \\
\text { seguintes princípios: [...] } \\
\text { Art. 15. Os sistemas de ensino assegurarão às unidades escolares públicas de educação } \\
\text { básica que os integram progressivos graus de autonomia pedagógica e administrativa } \\
\text { e de gestão financeira, observadas as normas gerais de direito financeiro público. } \\
\text { (BRASIL, 1996, n.p., grifo nosso). }\end{array}$ \\
\hline $\begin{array}{l}\text { Resolução No } 7 \\
\text { (BRASIL, 2004) }\end{array}$ & $\begin{array}{l}\text { Art. } 6^{\circ} \S 1^{\circ}[\ldots]-\text { Participar, assessorar, coordenar, liderar e gerenciar equipes } \\
\text { multiprofissionais de discussão, de definição e de operacionalização de políticas } \\
\text { públicas e institucionais nos campos da saúde, do lazer, do esporte, da educação, da } \\
\text { segurança, do urbanismo, do ambiente, da cultura, do trabalho, dentre outros (BRASIL, } \\
2004 \text {, p. 2, grifos nossos). }\end{array}$ \\
\hline $\begin{array}{l}\text { Resolução No } 2 \\
\text { (BRASIL, 2015) }\end{array}$ & $\begin{array}{l}\text { Art. } 13[\ldots] \text { a formação para o exercício integrado e indissociável da docência na } \\
\text { educação básica, incluindo o ensino e a gestão educacional. } \\
\S 2^{\circ} \text { Os cursos de formação deverão garantir nos currículos conteúdo específicos da } \\
\text { respectiva área de conhecimento ou interdisciplinares, seus fundamentos e } \\
\text { metodologias, bem como conteúdos relacionados aos fundamentos da educação, } \\
\text { formação na área de políticas públicas e gestão da educação [...]. (do urbanismo, do }\end{array}$ \\
\hline
\end{tabular}




\begin{tabular}{|c|c|}
\hline & a cultura, do trabalho, dentre outros (BRASIL, 2015, p. 11, grifos nossos). \\
\hline $\begin{array}{l}\text { Resolução No } 6 \\
\text { (BRASIL, 2018) }\end{array}$ & $\begin{array}{l}\text { Art. } 9^{\circ}[\ldots] \\
\text { VI - Mobilização efetiva de princípios que norteiam a formação inicial e continuada } \\
\text { nacionais comuns, tais como: [...] } \\
\text { e) gestão democrática; e [...] } \\
\text { Art. 14. A etapa específica para formação em Licenciatura deverá garantir nos currículos } \\
\text { interdisciplinares, seus fundamentos e metodologias, bem como conteúdos relacionados } \\
\text { aos fundamentos da educação e à formação na área de políticas públicas e gestão da } \\
\text { educação para o desenvolvimento das pessoas, das organizações e da sociedade. } \\
\text { Art. 16. [...] } \\
\text { b) pesquisa e estudo da legislação educacional, processos de organização e gestão } \\
\text { educacional, trabalho docente, políticas de financiamento educacional [...] (BRASIL, } \\
\text { 2018, p. } 4-5 \text {, grifos nossos). }\end{array}$ \\
\hline $\begin{array}{l}\text { Resolução No } 2 \\
\text { (BRASIL, 2019) }\end{array}$ & $\begin{array}{l}\text { Art. 12. No Grupo I, a carga horária de } 800 \text { horas deve ter início no } 1^{\circ} \text { ano, a partir da } \\
\text { integração das três dimensões das competências profissionais docentes - } \\
\text { conhecimento, prática e engajamento profissionais - como organizadoras do } \\
\text { currículo e dos conteúdos segundo as competências e habilidades previstas na BNCC } \\
\text { - Educação Básica para as etapas da Educação Infantil, do Ensino Fundamental e do } \\
\text { Ensino Médio (BRASIL, 2019, p. } 5 \text {, grifo nosso). } \\
\text { Parágrafo único. No Grupo I, devem ser tratadas ainda as seguintes temáticas: } \\
\text { IV - gestão escolar com especial ênfase nas questões relativas ao projeto pedagógico } \\
\text { da escola, ao regimento escolar, aos planos de trabalho anual, aos colegiados, } \\
\text { aos auxiliares da escola e às famílias dos estudantes (BRASIL, 2019, p. 5-6, grifo } \\
\text { nosso). }\end{array}$ \\
\hline
\end{tabular}

Fonte: Os autores, pesquisa documental.

A gestão democrática aludida pela LDB, em seus Artigos 14 e 15, evidencia um modelo de gestão centrado na autonomia das unidades escolares, indicando que elas devem se organizar para se autogerirem, ainda que reguladas pelos sistemas de ensino locais. Contudo, é importante destacar que, via de regra, a ocupação da função de diretor escolar, no Brasil, ocorre por meio de quatro mecanismos distintos: eleição, concurso público, indicação política ou processo seletivo interno (MEDEIROS, 2003). Embora não seja uma regra objetiva da LDB, tampouco uma prática predominante nos municípios e nos estados, há sistemas públicos de ensino que optam pela eleição dos diretores das unidades escolares com base nesse princípio.

A Resolução CNE N 7/2004, em seu Artigo $6^{\circ}$, trata das competências que deverão constituir o projeto pedagógico de formação do graduando em EF e aponta quais são as competências e as habilidades que devem ser adquiridas e desenvolvidas na formação desses profissionais. Em seu inciso $1^{\circ}$, consideramos que "[...] coordenar, liderar e gerenciar equipes multiprofissionais de discussão, de definição e de operacionalização de políticas públicas e institucionais [...]” (BRASIL, 2004, p. 2) subentende-se que essas podem ser características 
que, quando materializadas no currículo de formação inicial da área, deverão colaborar na atuação profissional dos egressos que virão a atuar como diretores de escola. Assim sendo, em tese, os cursos de licenciatura deveriam promover discussões sobre a gestão educacional e escolar de diferentes maneiras, inclusive como componente curricular em suas matrizes.

A Resolução $N^{o}$ 2/2015, que trata das licenciaturas em geral, sinaliza que os currículos de formação docente deverão ser capazes de ir além dos assuntos específicos de cada área, incluindo também "conteúdos relacionados aos fundamentos da educação" e aponta dentre eles, a gestão escolar. Por esse ângulo, compreendemos que a referida Resolução aponta para a formação de um professor, seja ele de qual disciplina for, capaz de atuar e intervir além da sala de aula, podendo colaborar no processo de gestão educacional e de políticas públicas. Para Puziol:

Uma formação que envolva o aprendizado sobre a gestão e organização dos estabelecimentos escolares de modo mais aprofundado, pode propiciar que profissionais de outras licenciaturas atuem com maior qualidade $\mathrm{e}$ responsabilidade no estabelecimento escolar em sua totalidade e não somente em sala de aula, que já é grande comprometimento (2018, p. 158).

Compreendemos que a Gestão deve estar situada com destaque no âmbito dos currículos da EF, exatamente para que seus egressos estejam em condições de ocupar a função de diretor escolar em pé de igualdade com os demais licenciados, bem como para que os princípios expressos nessas Resoluções se efetivem.

As novas DCNEF, publicadas em dezembro de 2018, além de preconizarem uma nova estrutura de currículo, acrescentam contribuições na temática da gestão escolar. Observamos que o Art. 9 aponta a gestão escolar como parte da "Mobilização efetiva de princípios" (BRASIL, 2018, p. 3) da formação. Conforme apresentado no Quadro 1, ressaltamos que aparece de forma bem específica que a temática da gestão é conteúdo dos currículos e como campo de "pesquisa e estudo" na formação inicial em EF.

Em dezembro de 2019, o CNE publicou uma nova Resolução que balizou a formação docente no país, denominada de "Base Nacional Comum para a Formação Inicial de Professores da Educação Básica” (BNC-Formação) (BRASIL, 2019, p. 1). Essa normativa reforça a necessidade de a gestão estar contemplada nos currículos das licenciaturas, estabelecendo que é uma das competências profissionais a serem desenvolvidas nos cursos que formam docentes para atuarem na Educação Infantil, no Ensino Fundamental e no Ensino 
Médio. A gestão passa, a partir dessa Resolução, a compor parte das 800 horas destinadas aos “[...] conhecimentos científicos, educacionais e pedagógicos e fundamentam a educação e suas articulações com os sistemas, escolas e práticas educacionais” (BRASIL, 2019, p. 5).

A temática da gestão escolar é recorrente nas orientações do Ministério da Educação (MEC) brasileiro. Aparenta, ainda, estar ganhando cada vez mais espaço ao longo do tempo. Ela deixa de ser tratada como "competências e habilidades" da formação docente em EF (BRASIL, 2004, p. 3), para se estabelecer como conteúdo de ensino e espaço de "pesquisa e estudo" da EF, a partir das orientações atuais (BRASIL, 2018, p. 5). Ressalvamos que as DCNEF não determinam que IES devam contemplar esses conhecimentos em forma de disciplina; no entanto, considerando o exposto, evidenciamos que ela ganha força e tenciona as IES a pensarem sobre como garantirem essa temática em seus currículos.

Todas essas legislações são reconhecidas por Noronha e Teixeira (2015) como sendo exigências à qualificação dos professores de EF para darem conta, por completo, das suas atribuições profissionais docente. Portanto, o debate acadêmico-científico da área bem como os currículos de licenciatura devem atentar-se a essas demandas legais/pedagógicas. Em consonância com Puziol (2018, p. 168-169), acreditamos que a possibilidade de abordar, de forma mais detida e específica, as dimensões da gestão educacional e escolar em todos os cursos de licenciatura, “[...] pode se configurar numa importante ação docente formativa que favoreça o entendimento da realização das políticas educacionais no contexto da prática, dando maior materialidade à legislação educacional".

Dada a recente publicação, uma análise mais profunda sobre o impacto das novas DCNEF na temática da Gestão escolar só será possível à medida que as IES reformularem seus itinerários formativos, dentro do prazo de dois anos previsto para o seu cumprimento em definitivo.

\section{PRODUÇÃO ACADÊMICA NA ÁREA DA EDUCAÇÃO FÍSICA SOBRE GESTÃo ESCOLAR}

Na busca por produções acadêmicas que pudessem ampliar nossa compreensão sobre o objeto, bem como estabelecer as fronteiras do que já havia sido produzido pela comunidade científica da área, lançamo-nos a procura por publicações. Romanowski e Ens (2006) defendem o mapeamento do conhecimento já produzido, nas diferentes áreas, para que essa 
iniciativa contribua com a realização de um balanço que desvende e examine o conhecimento já elaborado e apontem os enfoques, os temas mais pesquisados e as lacunas existentes.

A discussão sobre a produção científica relacionada ao tema abordado neste artigo inicia com a constatação de outros autores dedicados a essa tarefa, que apontam uma baixa produção acadêmica na área no tocante à relação do professor de EF com a gestão de escolas (CÁRDENAS; FEUERSCHÜTTE, 2014; ALATZOGLOU; ATHANAILIDIS; SAMPANIS, 2013; MENDES; BACCIN; DALL'IGNA, 2012; ILHA; KRUG, 2008). Eles observam ainda haver muito a ser explorado nas pesquisas sobre o assunto. Conforme sentenciam Cárdenas e Feuerschütte (2014): “A formação em Educação Física relacionada à gestão, ao que aparenta, foi objeto de escassas investigações cientificas”.

Souza (2006) apresenta um levantamento de teses e de dissertações produzidas entre 1981 e 2001, combinando os bancos de dados da Associação Nacional de Pesquisas em Educação (ANPEd) e da Capes, de todas as áreas do conhecimento. Foram encontrados 183 trabalhos sobre gestão escolar, ficando evidente que nenhum desses foi defendido em Programas de EF. Essa constatação reforça nossos argumentos de um quadro de escassez de publicações que abordam essa temática na área.

Alatzoglou, Athanailidis e Sampanis (2013), em um estudo quantitativo realizado na Grécia sobre a capacidade administrativa do professor de EF atuando como diretor escolar, destacam que: “A maior limitação é que os resultados não podem ser comparados com outros estudos similares" (ALATZOGLOU; ATHANAILIDIS; SAMPANIS, 2013, p. 3, tradução nossa), levando-nos a perceber que tanto a atuação de professores de EF frente à gestão de escolas seria uma temática relevante, quanto a baixa produção acadêmica se repete também no referido país.

As produções encontradas em nossos levantamentos debruçaram-se em descrever a atuação dos docentes de Educação Física frente à gestão educacional (MOLINA NETO, 1998; QUINTANA, 2010; MENDES; BACCIN; DALL'IGNA, 2012; KRÖNING, 2016; LOPES, 2016; PETERLE, 2017), seja ela diretamente na escola ou em algum órgão gestor.

Conforme descrito no método, realizamos buscas em oito periódicos científicos do campo da EF com melhor classificação no WebQualis da Capes (2013-2016). Apresentamos, no Quadro 2 a seguir, os dados levantados nesse processo. 
Quadro 2 - A gestão escolar nos periódicos da área

\begin{tabular}{|c|c|c|c|}
\hline Periódico & Periodicidade & Artigos observados & $\begin{array}{c}\text { Educação Física e Gestão } \\
\text { escolar }\end{array}$ \\
\hline Licere & $1999-2007$ & 678 & - \\
\hline Motrivivência & $1988-2017$ & 853 & - \\
\hline Motriz & $1995-2015$ & 552 & MOLINA NETO (1998) \\
BACCIN; \\
Movimento & $1994-2017$ & 1019 & $\begin{array}{l}\text { MENDES; } \\
\text { DALL'IGNA (2012) }\end{array}$ \\
\hline Pensar a Prática & $1998-2017$ & 792 & - \\
\hline RBCE & $1979-2017$ & 1464 & - \\
\hline RBEFE & $2004^{5}-2017$ & 656 & - \\
\hline Revista de EF da UEM & $1989-2017$ & 917 & $\mathbf{2}$ \\
\hline Total & & $\mathbf{6 9 3 1}$ & \\
\hline
\end{tabular}

Fonte: Os autores, pesquisa bibliográfica.

No conjunto de publicações levantadas, identificamos apenas dois artigos que discutem gestão escolar, ambos publicados na revista Movimento. No primeiro trabalho, Molina Neto (1998) ouviu 20 professores de Educação Física de escolas públicas de Porto Alegre, buscando identificar suas práticas e seus conhecimentos. O segundo trata da relação de professores com formação em EF e um órgão gestor de educação da cidade de Acalifa, no Rio Grande do Sul. De autoria de Mendes, Baccin e Dall'Igna (2012), tem como título Da escola para a gestão da rede de ensino: como o professor se torna um supervisor? e a utilização de uma metodologia qualitativa, composta por entrevistas e análise documental para atingir os objetivos.

Observamos que o artigo de Molina Neto (1998) centra esforços em uma visão ampla da atuação do professor de EF, trata de assuntos diversos, tais como: a falta de reconhecimento profissional; especificidade do trabalho na escola pública e do trabalho com o corpo; aborda também questões como a liberdade relativa que gozam dentro da organização da disciplina e o isolamento desses profissionais na escola.

Molina Neto (1998) discutiu a participação política dos docentes da área dentro das escolas, percebendo na fala dos profissionais ouvidos temas políticos e sindicais. $\mathrm{O}$ autor aponta também que, devido à especificidade da EF, os professores desenvolvem uma "relação muito próxima" com os alunos, o que os daria um "espaço privilegiado" dentro da 
organização política das escolas. O pesquisador apresenta dados que refletem a participação dos docentes em cargos de Direção/Vice-direção, comparando as redes municipal de Porto Alegre/RS e a estadual do Rio Grande do Sul. Nesse caso, o autor observou que respectivamente 22,5\% e 6,2\% dos diretores são docentes da área. Molina Neto (1998) atribui essa diferença de percentuais ao fato de os alunos participarem votando nas eleições municipais, fato que não ocorre no âmbito estadual.

O estudo de Mendes, Baccin e Dall'Igna (2012) retrata a mediação entre os supervisores de uma Secretaria Municipal de Educação e os professores de EF que atuam no referido município. Esse trabalho ressalta as nuances encontradas no tocante aos projetos de governos das sucessivas administrações municipais. Os autores também fazem questão de mencionar o pouco interesse que a comunidade vem demonstrando sobre essa temática, ao afirmarem que: "A relevância do estudo desse tema prende-se ao reduzido número de pesquisas que discutem a gestão das redes de ensino e à escassez dessas investigações na Educação Física” (MENDES; BACCIN; DALL'IGNA, 2012, p. 97), convergindo com o nosso levantamento atual, exposto no Quadro 2.

Apesar disso, é interessante observarmos que, durante a pesquisa bibliográfica, percebemos publicações que focalizam a participação de professores de Educação Física em cargos de gestão em espaços não escolares. Essa observação coaduna com o que é apresentado por Cárdenas e Feuerschütte (2014), ao destacarem o crescente número de publicações que abordam a temática da gestão esportiva por profissionais de Educação Física no Brasil. Noronha e Teixeira (2015) concluem que a gama de estudos dedicados a essa temática decorre do entendimento de que se trata de uma responsabilidade do profissional de Educação Física a gestão esportiva.

Inserindo-se os descritores: professor de Educação Física e gestão escolar, nas bases de dados do Google Acadêmico e SciELO, notamos publicações em periódicos de outras áreas do conhecimento; contudo, parecem seguir a mesma pista da baixa produção de trabalhos dentro da temática. Como parte das conclusões de seu artigo sobre a participação do professor de EF na gestão escolar, Ilha e Krug (2008) apontam a necessidade de mais produção na área e complementam “[...] que os estudos nessa linha Educação Física - Gestão Escolar/Educacional são poucos". 
Ao buscar teses e dissertações defendidas em Programas de Pós-Graduação em Educação Física (PPGEFs), por meio da Plataforma Sucupira/Capes ${ }^{6}$, localizamos 36 Programas com 58 cursos oferecidos, entre Doutorado, Mestrado Acadêmico e Mestrado Profissional. Após filtrados pelas áreas de concentração e linhas de pesquisas com foco nas subáreas sociocultural e pedagógica, restaram 20 cursos.

Após examinarmos cada repositório disponibilizado pelos PPGEFs, identificamos 2.993 teses e dissertações, das quais apenas quatro dissertações contemplaram a temática EF/Gestão Escolar, conforme explicitado no Quadro 3.

Quadro 3 - EF e Gestão Escolar na Pós-Graduação

\begin{tabular}{|c|c|c|c|c|c|}
\hline \multirow{2}{*}{ Instituição } & \multicolumn{2}{|c|}{ Trabalhos observados } & \multicolumn{2}{|c|}{$\begin{array}{c}\text { Trabalhos relacionados } \\
\text { ao objeto } \\
\end{array}$} & \multirow{2}{*}{ Autor e ano de defesa } \\
\hline & Dissertações & Teses & Dissertações & Teses & \\
\hline UPE & 74 & 0 & - & - & \\
\hline USP* & 87 & 50 & - & - & \\
\hline UNICAMP* & 106 & 0 & - & - & \\
\hline UEM/UEL & 107 & 0 & - & - & \\
\hline UNESP* & 384 & 0 & - & - & \\
\hline UFMT & 25 & 0 & - & - & \\
\hline UFMG** & 18 & 0 & - & - & \\
\hline UFPel & 203 & 1 & 2 & - & $\begin{array}{l}\text { QUINTANA (2010) } \\
\text { KRÖNING (2016) }\end{array}$ \\
\hline UFPE & 6 & 0 & - & - & \\
\hline UFSC & 416 & 89 & - & - & \\
\hline UFSM & 52 & 0 & - & - & \\
\hline UFSCAR** & 23 & 0 & & & \\
\hline UFES & 199 & 1 & 1 & - & PETERLE (2017) \\
\hline UFRJ $* * *$ & - & - & - & - & \\
\hline UFRN & 91 & 0 & - & - & \\
\hline UFRGS & 552 & 135 & 1 & - & LOPES (2016) \\
\hline UNIVASF & 17 & 0 & - & - & \\
\hline UNIMEP & 186 & 0 & - & - & \\
\hline UNIVERSO**** & - & - & - & - & \\
\hline USJT & 167 & - & - & - & \\
\hline Soma parcial & 2713 & 276 & 4 & - & \\
\hline Total & \multicolumn{2}{|c|}{2989} & \multicolumn{2}{|c|}{4} & \\
\hline \multicolumn{6}{|c|}{$\begin{array}{r}* \text { Levantamento pela aplicação de filtros na biblioteca online da instituição } \\
* * \text { Mestrado profissional em Educação Física } \\
* * * \text { Arquivos não disponíveis para pesquisa }\end{array}$} \\
\hline
\end{tabular}


A partir da leitura de cada uma das dissertações encontradas, extraímos elementos gerais desses trabalhos em busca de ampliar nossa compreensão do objeto. Quintana (2010) identificou como os professores de EF se constituíram gestores das escolas da Rede Estadual de Ensino da cidade de Pelotas/RS, entre os anos de 2007 e 2009. A metodologia utilizada foi uma pesquisa qualitativa, que entrevistou nove gestores, sob um roteiro semiestruturado que visou compreender motivos pessoais e profissionais para buscarem ocupar essa função. $\mathrm{O}$ autor concluiu que a formação inicial em EF não fora suficiente para o exercício da função. Observou, ainda, que fatores pessoais determinaram a escolha da profissão; contudo, a interlocução com os colegas de trabalho é o que mais os influenciaram na opção por atuarem na gestão. O pesquisador ressalvou que, apesar das diretoras conhecerem as práticas de gestão democrática, nem todas as aplicam e que as famílias provenientes de camadas menos favorecidas economicamente se mostram mais participativas e preocupadas com a gestão da escola, bem como com a educação oferecida a seus filhos.

O trabalho de Lopes (2016) buscou compreender como docentes de EF que atuam como diretores ou vice-diretores assumem, significam e experienciam a gestão escolar na Rede Municipal de Ensino de Porto Alegre/RS. Foram utilizadas narrativas de três docentes que ocupavam essas funções no período de agosto a dezembro de 2015. As narrativas produzidas pelos "professores-diretores" assinalam os percursos e as singularidades de cada um dos sujeitos, fazendo menções sobre a sua formação e sobre o contexto social, histórico e político de cada um. Em suas considerações finais, a autora afirma que a mudança na conjuntura política de organização da educação na Rede Municipal de Porto Alegre influencia na participação dos professores de EF em cargos relativos à gestão escolar. O estudo aponta também que fatores como a boa relação mantida por esses professores com alunos e famílias são preponderantes na chegada ao cargo de diretor.

As narrativas que compõem o trabalho de Lopes (2016) destacam, ainda, que os sujeitos dessa pesquisa afirmam não se lembrar de disciplinas que os preparassem para essa atuação, mas consideram que outros elementos como a participação em diretórios acadêmicos e espaços políticos durante sua formação inicial contribuíram para essas aspirações. A referida autora produz uma crítica considerando necessária uma formação mais ampla nos cursos de EF, pois, para ela, ficou explícito que os envolvidos aprendem apenas pela prática cotidiana sobre gestão escolar. 
Os trabalhos de Kröning (2016) - Formação Continuada em Educação Física Escolar: ações, percepções e desafios da gestão educacional - e de Peterle (2017) - Formação, gestão e inclusão: a experiência da Educação Física no município de Viana - apesar de anunciarem a relação entre EF e Gestão, apresentam-se no âmbito da gestão educacional ampla. O primeiro evidencia contribuições na área da formação continuada em EF escolar no município de Pelotas/RS. O segundo estudo trata da formação continuada específica no campo da inclusão desenvolvida na cidade de Viana/ES. Ambas as pesquisas contribuem para uma visão mais ampliada de gestão educacional, mas não tratam da presença direta do professor de EF nessa função.

As dissertações analisadas, sutilmente, responsabilizam a formação docente em EF pela dificuldade em exercer a gestão escolar. Embora não mencione com clareza a ausência de disciplinas específicas para tal, bem como quando os sujeitos participantes foram formados em EF (se antes ou após as Diretrizes que identificamos recomendarem a gestão como eixo da formação em licenciatura), os autores problematizam as deficiências no processo de "preparação" para o exercício profissional pleno, em todos os espaços possíveis para quem cursa EF. Acabam por expor ainda que, nos casos analisados, a formação não é um fator de encorajamento para a assunção da gestão. Fatores outros, como um suposto perfil enxergado pelos demais colegas da escola, atuação política pregressa; envolvimento em formações continuadas das próprias redes, têm se constituído como motivantes para o desafio da gestão escolar.

Esse nosso entendimento, encontramos respaldo na pesquisa de Silva e Molina Neto (2012), que estudaram a participação de docentes de EF em diversos espaços de liderança/gestão (direção de escolas, sindicatos, parlamento, movimentos sociais) no Rio Grande do Sul, provocados pela prevalência de sujeitos com essa formação a frente desses espaços. Os pesquisadores concluem que "[...] há uma multiplicidade de determinações da prática social, das relações familiares e da formação inicial que se sintetizam e contribuem para a formação política de professores de Educação Física" (SILVA; MOLINA NETO, 2012, p. 870). Os autores compreendem que a "formação política", proveniente de um "currículo oculto", é peça determinante para mobilizar os profissionais da EF para essas tarefas. 


\section{A GESTÃO ESCOLAR NOS PERFIS DE EGRESSO E NAS DISCIPLINAS DOS CURSOS DE FORMAÇÃO EM EDUCAÇÃO FÍSICA NA GRANDE VITÓRIA}

Os cursos de formação inicial têm impacto decisivo sobre a atuação docente. Portanto, pesquisar os elementos constitutivos das propostas curriculares de cursos de Ensino Superior podem contribuir para compreendermos as aproximações e os distanciamentos com as exigências legais e as demandas do campo profissional. O perfil do egresso de um curso traduz a consolidação dos objetivos traçados pela instituição em relação ao seu currículo de formação acadêmica; em outras palavras, uma síntese textual do conjunto de conhecimentos e habilidades que o discente deve adquirir ao se formar na perspectiva anunciada pela faculdade. Por meio dos títulos das disciplinas, buscamos as unidades curriculares que mantivessem relação com nosso objeto de estudo, procurando compreender a materialização desses perfis no rol de disciplinas oferecidas, ou, ainda, identificação da presença desse tema no currículo mesmo quando não anunciado.

Observando as perspectivas trazidas pelos documentos orientadores e pela legislação, percebemos que cada IES precisa tomá-los como base, porém possuem certo grau de autonomia para definir seus currículos. Dentre as oito IES pesquisadas, a gestão escolar é encontrada no perfil de egresso da Católica de Vitória, em duas disciplinas oferecidas pela Faculdade Pitágoras e uma disciplina ofertada pela Fabra.

No perfil de egresso da Católica de Vitória - única IES que faz menção textual da gestão -, notamos que a função de "gestor" faz parte do campo de atuação previsto para seus discentes. $\mathrm{O}$ documento afirma ainda que é preciso "[...] dominar as metodologias de ensino e estratégias de aula, incluindo as novas tecnologias educacionais, considerando os âmbitos do ensino e da gestão". Isso leva-nos a crer que a temática da gestão escolar é contemplada no curso oferecido. Embora esteja presente no perfil de egresso, a Católica de Vitória não oferece uma disciplina especifica sobre gestão escolar. Contudo, detectamos, na bibliografia da disciplina intitulada "Estrutura e funcionamento do ensino", o livro Educação escolar: políticas, estrutura e organização, de Libâneo, Oliveira e Toschi (2006), o qual trata, entre outros assuntos, da inter-relação entre a prática docente do professor, a organização das estruturas de ensino e a gestão das escolas. 
Identificamos que a Fabra e a Pitagorás ofertam disciplinas que dialogam diretamente com a temática, intituladas em ambas as instituições "Gestão Educacional”. A primeira IES, inclusive, exige a realização de um estágio nessa área. Cabe ressaltarmos que não nos foi fornecido acesso à ementa dessas disciplinas, fato que nos permitiria desenvolver uma análise mais detida.

Em linhas gerais, percebemos que os textos dos perfis de egressos são muito abrangentes, possivelmente pelo interesse das IES em ofertar a formação mais ampla possível, podendo, assim, atender a diversas demandas do mercado de trabalho. É provável que a intenção dessas instituições seja a captação de um maior número de estudantes para seus cursos, tendo em vista que são faculdades privadas.

Aparentemente, o fato de um número crescente de professores de EF assumirem postos na gestão de escolas em Vitória não tem repercutido de modo significativo no currículo dessas IES. Esse fato não se restringe à capital capixaba. Pela nossa trajetória como professores, ex-gestores e pesquisadores na/da EF no Espírito Santo, temos conhecimento de que existem um grande número de docentes com essa formação atuando na direção de escolas em outras redes e como Secretários de Educação em algumas cidades ${ }^{7}$ do interior do Estado.

Defendemos que os cursos de EF devem oferecer uma formação ampla, em permanente diálogo com as orientações legais vigentes. Com base em Sacristán (2000), compreendemos que o currículo precisa dialogar com as demandas sociais, pois ele se configura como criação social; deve estar, portanto, intimamente ligado ao contexto no qual está inserido. Ainda, segundo o referido autor, nenhum currículo é neutro, pois as pessoas que o compõem estão permeadas por seus próprios interesses e construções históricas, refletindo seus anseios e suas necessidades.

Sobre a repercussão das DCNEF (Resolução CNE N 7/2004), por um lado, nos currículos de licenciatura em Educação Física no contexto capixaba, Marques e Figueiredo (2014) destacam que as orientações contidas nessas diretrizes não repercutem de maneira automática ou rígida neles. Para as autoras, os currículos

[...] apresentaram diferentes e ambíguas formas de interpretação das diretrizes curriculares para os cursos de educação física e confirmam o campo de manobra, omissões, interpretações e materialização de dimensões epistemológicas e políticas, para além daquelas sugeridas nas orientações legais (MARQUES; FIGUEIREDO, 2014, p. 40). 
Morschbacher e Veronez (2015, p. 112-113), por outro lado, ao estudarem os currículos reformulados após a vigência das DCNEF de 2004 de algumas IES, avaliam que “[...] no processo de seleção do conhecimento, disciplinas são incluídas ou suprimidas (negadas) com base no parâmetro dos espaços de trabalho".

A discussão sobre gestão escolar parece ser incipiente nos currículos das IES da GV. Ao que tudo indica, embora o campo profissional local tenha sinalizado essa demanda, as IES ainda não potencializaram essa temática na formação de seus discentes. Essa lacuna na formação inicial parece estar repercutindo na necessidade de apostar na formação continuada. A Secretaria Municipal de Educação de Vitória/ES (Seme) vem promovendo formação específica para os professores de sua rede que se propõem a gerir escolas no município. Verificamos na Portaria Seme 019/2017 ${ }^{8}$, a obrigatoriedade da participação em um curso instituído como pré-requisito às candidaturas no pleito de 2017 (VITÓRIA, 2017a). A modalidade escolhida fora a semipresencial e totalizou 40 horas de formação. O objetivo geral descrito no projeto era: "Qualificar os profissionais do magistério da rede municipal de Vitória, proporcionando estudos, discussões e reflexões nos processos pertinentes à gestão da escola pública" (VITÓRIA, 2017b, p. 4).

Observamos um movimento que ocorre dentro da administração da educação pública do município em prol de instrumentalizar seus futuros gestores de escolas para as ações que lhes serão imputadas no desempenho da função. Observamos ainda que a formação é destinada a todos os candidatos - professores formados em diversas áreas do conhecimento. Essa ausência de discussões mais sistematizadas e aprofundadas na formação inicial, aparentemente em todas as licenciaturas, pode estar associada à constituição desse "curso preparatório", para aqueles que desejam concorrer nas eleições.

Ainda que todas as licenciaturas adotassem a dimensão da gestão escolar com mais solidez em seus currículos, isso não excluiria a necessidade de formação permanente para aqueles que se lançam nesse desafio. Para Lück (2009, p. 25), “[...] não se pode deixar de considerar como fundamental para a formação de gestores, um processo de formação continuada, em serviço, além de programas especiais e concentrados sobre temas específicos".

A formação continuada constitui-se em uma alternativa viável para atualização e qualificação profissional permanente; ao mesmo tempo, ela acaba servindo, recorrentemente, 
como um instrumento de superação das lacunas diagnosticadas na formação inicial. No caso da relação EF-Gestão escolar em Vitória/ES, parece que prevalece a segunda opção.

\section{CONSIDERAÇÕES FINAIS}

A gestão escolar tem se apresentado como possibilidade no campo de atuação profissional do professor formado em Educação Física, especialmente em contextos onde são realizadas eleições diretas para escolha dos diretores escolares. Essa participação é endossada pela legislação que imputa ao professor papel na organização administrativa da escola, desde a elaboração dos projetos à intermediação da relação com as famílias, indicando ser o docente responsável por funções correlatas à gestão em uma visão macro da organização escolar (BRASIL, 1996).

Observamos que as orientações legais para formação de professores de EF vêm gradualmente ampliando o espaço dedicado à gestão escolar. Destacando os apontamentos contidos nas DCNEF, a temática deixa de figurar apenas como "competências e habilidades" (BRASIL, 2004, p. 3), para em sua publicação mais recente aparecer claramente como campo de "estudo e pesquisa" (BRASIL, 2018, p. 5). Compreendemos que esse fato deveria/deve impactar nos currículos de formação de docentes da área.

No campo da produção acadêmica, constatamos um número muito reduzido de publicações na temática que relaciona o professor de EF frente à gestão escolar. O mesmo se repete nas investigações acerca dos currículos ofertados em instituições da Grande Vitória/ES. Os trabalhos encontrados corroboram não somente com nossas observações de que a presença do profissional de EF atuando como diretor de escola se repete em outras regiões do país (até mesmo no exterior), mas também com o fato de esses estudos não considerarem a formação inicial na área como capaz de suprir as necessidades no que tange à gestão escolar.

De acordo com os documentos que orientam os cursos de licenciatura no Brasil, a gestão escolar deve fazer parte dos currículos de formação dos professores que irão atuar na Educação Básica. Entretanto, essa discussão foi percebida de maneira superficial nos perfis dos egressos/matrizes curriculares dos cursos analisados. Com isso, percebemos indícios de que a temática Gestão Escolar tem sido negligenciada pela maioria das IES pesquisadas, onde, mesmo quando mencionada no perfil dos egressos, ocupa um papel periférico na composição do currículo, ficando oculta dentro das matrizes curriculares. 
Todavia, fazemos duas ressalvas. Na primeira, observamos que a baixa presença de disciplinas ou de informações no perfil do egresso sobre a gestão escolar não é garantia de que essa discussão seja inexistente nos cursos pesquisados, podendo se configurar como um tema inserido em diferentes componentes da formação, tendo em vista que, em nenhuma das resoluções analisadas mencionam a obrigatoriedade da composição de uma disciplina curricular específica abordando essa temática. Na segunda, verificamos que, mesmo com as atualizações das DCNEF, existe um tempo necessário para que possam ser absorvidas nas reestruturações curriculares das IES que formam os docentes da área; em tempo, consideramos que ainda são muito recentes essas orientações para que possam causar grande impacto na formação.

Analisamos que a baixa produção acadêmica no campo da EF, no que tange à gestão escolar, deve-se a fatores como: os currículos de formação inicial pouco discutem o tema, e parte dos estudos produzidos se localizam em periódicos e programas de Pós-Graduação de outras áreas do conhecimento.

Ainda que em Vitória/ES verifique-se um processo de ocupação considerável de docentes com formação em EF nos cargos de diretores escolares na rede pública, bem como a LDB, as DCN para os cursos de licenciatura e as DCNEF ressaltem a gestão escolar como um dos campos de atuação profissional, isso não vem se materializando de forma expressiva em perfis de egressos e de disciplinas nos cursos de formação inicial nas IES da região metropolitana da GV e na produção acadêmico-científica geral e capixaba.

Identificamos, no âmbito municipal, um movimento formativo que visa instrumentalizar os futuros gestores das unidades de ensino; além disso, observamos que esse curso engloba professores formados em todas as licenciaturas, o que pode indicar duas situações possíveis identificadas pela Seme: a) tentativa de suprir uma lacuna deixada pelos cursos de formação inicial (licenciaturas) de modo geral dentro do campo da gestão; b) fornecer uma instrumentalização básica e específica para atuarem como gestores nessa municipalidade.

Considerando o exposto, indicamos haver uma divergência entre o campo de atuação/orientações e formação em EF/produção acadêmica da área. Em investigações futuras, pretendemos analisar os fatores que têm levado os professores de Educação Física a ocuparem a função de Diretor escolar e suas representações sobre essa posição. 


\section{REFERÊNCIAS}

ALATZOGLOU, Athanasios; ATHANAILIDIS, Ioannis; SAMPANIS, Michail. The administrative management capacity of the physical educations teachers as a school principal. Journal of Novel Physiotherapies, v. 3, n. 5, p. 1-4, 2013.

BRASIL. Lei N 9.394, de 20 de dezembro de 1996. Estabelece as diretrizes e bases da educação nacional. Brasília: Presidência da República, Casa Civil, Subchefia para Assuntos Jurídicos, [1996]. Disponível em: http://www.planalto.gov.br/ccivil_03/leis/19394.htm. Acesso em: 2 fev. 2020.

BRASIL. Resolução $\mathbf{N}^{\mathbf{0}}$ 7, de 31 de março de 2004. Institui as Diretrizes Curriculares Nacionais para os cursos de graduação em Educação Física, em nível superior de graduação plena. Brasília: Conselho Nacional de Educação, Câmara de Educação Superior, [2004]. Disponível em: http://portal.mec.gov.br/cne/arquivos/pdf/ces0704edfisica.pdf. Acesso em: 2 fev. 2020.

BRASIL. Resolução $\mathbf{N}^{\mathbf{2}} \mathbf{2}$, de $\mathbf{1}^{\mathbf{0}}$ de julho de 2015. Define as Diretrizes Curriculares Nacionais para a formação inicial em nível superior (cursos de licenciatura, cursos de formação pedagógica para graduados e cursos de segunda licenciatura) e para a formação continuada. Brasília: Ministério da Educação, Conselho Nacional de Educação, Conselho Pleno, [2015]. Disponível em: http://portal.mec.gov.br/docman/agosto-2017-pdf/70431-res-cne-cp-002-03072015-pdf/file. Acesso em: 2 fev. 2020.

BRASIL. Resolução No 6 , de 18 de dezembro de 2018. Institui Diretrizes Curriculares Nacionais dos Cursos de Graduação em Educação Física e dá outras providências. Brasília: Ministério da Educação, Conselho Nacional de Educação, Câmara de Educação Superior, [2018]. Disponível em:

http://portal.mec.gov.br/index.php?option=com docman\&view=download\&alias=104241rces006-18\&category_slug=dezembro-2018-pdf\&Itemid=30192. Acesso em: 2 fev. 2020.

BRASIL. Resolução No 2, de 20 de dezembro de 2019. Define as Diretrizes Curriculares Nacionais para a Formação Inicial de Professores para a Educação Básica e institui a Base Nacional Comum para a Formação Inicial de Professores da Educação Básica (BNCFormação). Brasília: Ministério da Educação, Conselho Nacional de Educação, Conselho Pleno, [2019]. Disponível em:

https://apoiocoordenadoriascursosgraduacao.paginas.ufsc.br/files/2020/01/Resolu\%C3\%A7\% C3\%A3o-CNE_CP-2_20dez2019.pdf. Acesso em: 2 fev. 2020.

CÁRDENAS, Alfredo Ribeiro; FEUERSCHÜTTE, Simone Ghisi. Formação, relacionada à gestão, oferecida em cursos de graduação em Educação Física: Um olha qualitativo sobre currículos, disciplinas e ementas. Pensar a Prática, Goiânia, v. 17, n. 4, out./dez. 2014.

ILHA, Franciele Roos da Silva; KRUG, Hugo Norberto. O professor de educação física e sua participação na gestão escolar: contribuições para a formação profissional. Revista E-

Curriculum, São Paulo, v. 4, n. 1, dez. 2008.

KRÖNING, Eliana Köhler. Formação Continuada em Educação Física Escolar: ações, percepções e desafios da gestão educacional. 2016. Orientador: Mario Renato de Azevedo 
Júnior. Dissertação (Mestrado em Educação Física) - Universidade Federal de Pelotas, Pelotas, 2016.

LAKATOS, Eva Maria; MARCONI, Marina de Andrade. Fundamentos da metodologia científica. 5. ed. São Paulo: Atlas, 2003.

LAROCCA, Priscila; JUNGES, Kelen dos Santos. A constituição do professor no exercício da profissão. Intermeio, Campo Grande, v. 10, n. 20, p. 42-61, 2004.

LIBÂNEO, José Carlos; OLIVEIRA, João Ferreira; TOSCHI, Mirza Seabra. Educação escolar: políticas, estrutura e organização. 3. ed. São Paulo: Cortez, 2006.

LOPES, Andressa Ceni. Da sala de aula à gestão escolar: professores de Educação Física em equipes diretivas de escolas públicas da Rede Municipal de Ensino de Porto Alegre (RMEPOA). 2016. Orientador: Elisandro Schultz Wittizorecki. Dissertação (Mestrado em Ciência do Movimento Humano) - Universidade Federal do Rio Grande do Sul, Porto Alegre, 2016.

LÜCK, Heloísa. Dimensões de gestão escolar e suas competências. Curitiba: Editora Positivo, 2009.

MARQUES, Fabíola Borel; FIGUEIREDO, Zenólia Christina Campos. Diretrizes curriculares nacionais e suas repercussões nos currículos de formação docente em educação física. Motrivivência, Florianópolis, v. 26, n. 43, p. 30-43, dez. 2014.

MEDEIROS, Isabel Letícia Pedros. Gestão democrática na Rede Municipal de Educação de Porto Alegre de 1989 a 2000: a tensão entre reforma e mudança. 2003. Orientadora: Maria Beatriz Moreira Luce. Dissertação (Mestrado em Educação) - Faculdade de Educação, Universidade Federal do Rio Grande do Sul, Porto Alegre, 2003.

MENDES, Valdelaine; BACCIN, Ecléa Vanessa Canei; DALL'IGNA, Maria Antonieta. Da escola para a gestão da rede de ensino: como o professor se torna um supervisor?. Revista Movimento, Porto Alegre, v. 18, n. 3, p. 95-118, jul./set. 2012.

MOLINA NETO, Vicente. A prática dos professores de educação física das escolas públicas de Porto Alegre. Movimento, Porto Alegre, ano V, n. 9, p. 31-46, 1998.

MORSCHBACHER, Márcia; VERONEZ, Luiz Fernando Camargo. Diretrizes curriculares nacionais: impactos sobre os currículos de formação de professores de educação física.

Revista Pedagógica, Chapecó, v. 17, n. 35, p. 101-118, maio/ago. 2015.

NORONHA, Vânia; TEIXEIRA, Daniel Marangon Duffles. Gestão e avaliação: desafios para a educação física como área de conhecimento. Revista @ rquivo Brasileiro de Educação, Belo Horizonte, v. 3, n. 5, p. 84-101, jan./jul. 2015.

PETERLE, Ludmila Lima. Formação, gestão e inclusão: a experiência da Educação Física no município de Viana. 2017. Orientador: José Francisco Chicon. Dissertação (Mestrado em Educação Física) - Universidade Federal do Espírito Santo, Vitória, 2017. 
PUZIOL, Jeinni Kelly Pereira. Formação inicial em nível superior dos cursos de licenciatura: em perspectiva a gestão educacional e escolar a partir da resolução CNE/CP no 2/2015. Momento - Diálogos em Educação, Rio Grande, v. 27, n. 2, p. 157-171, maio/ago. 2018.

QUINTANA, Júlia Coelho. O professor de Educação Física na direção da escola pública estadual. 2010. Orientadora: Valdelaine da Rosa Mendes. Dissertação (Mestrado em Educação Física) - Universidade Federal de Pelotas, Pelotas, 2010.

ROMANOWSKI, Joana Paulin; ENS, Romilda Teodora. As pesquisas denominadas do tipo "estado da arte" em educação. Diálogo Educação, Curitiba, v. 6, n. 19, p. 37-50, set./dez. 2006.

SACRISTÁN, José Gimeno. O currículo: uma reflexão sobre a prática. 3. ed. Porto Alegre: Artmed, 2000.

SILVA, Guilherme Gil da Silva; MOLINA NETO, Vicente. Um estudo sobre a formação política de professores de educação física. Revista Brasileira de Ciências do Esporte, Florianópolis, v. 34, n. 4, p. 859-873, jul./set. 2012.

SOUZA, Ângelo Ricardo de. Os caminhos da produção científica sobre gestão escolar no Brasil. Revista Brasileira de Política e Administração da Educação - RBPAE [online], v. 22, n. 1, p. 13-39, jan./jun. 2006.

VITÓRIA (Cidade). Portaria SEME nº 019/2017. Homologar a Resolução No 02/2017, do Conselho Municipal de Educação de Vitória - COMEV, que dispõe sobre o processo de eleição para provimento da Função Gratificada de Diretor(a) nas Unidades de Ensino da Rede Pública Municipal de Vitória. Diário Oficial do Município de Vitória/ES: Vitória, ES, n. 961, p. 5, 17 maio 2017a.

VITÓRIA (Cidade). Secretaria Municipal de Educação de Vitória/ES. Projeto Eleiçãa de Diretores. Vitória: PMV/SEME, 2017b.

\section{NOTAS}

${ }^{1}$ A região da Grande Vitória é composta pelos seguintes municípios: Vitória, Vila Velha, Cariacica, Serra, Viana e Guarapari.

${ }^{2}$ Licere, Motrivivência, Motriz, Movimento, Pensar a Prática, Revista Brasileira de Ciências do Esporte (RBCE), Revista Brasileira de Educação Física e Esporte (RBEFE), Revista da Educação Física/UEM.

3 Capes - Autarquia responsável por organizar o sistema de Pós-Graduação no País, fato que inclui a estratificação das revistas científicas em que são publicados os estudos dos docentes vinculados aos Programas de Mestrado e Doutorado no país.

${ }^{4}$ O levantamento ocorreu nos programas das seguintes instituições: Universidade de Pernambuco (UPE), Universidade de São Paulo (USP), Universidade Estadual de Campinas (UNICAMP), Universidade Estadual de Maringá/Universidade Estadual de Londrina (UEM/UEL), Universidade Estadual Paulista Júlio de Mesquita Filho (UNESP), Universidade Federal de Mato Grosso (UFMT), Universidade Federal de Minas Gerais (UFMG), Universidade Federal de Pelotas (UFPel), Universidade Federal de Pernambuco (UFPE), Universidade Federal de Santa Catarina (UFSC), Universidade Federal de Santa Maria (UFSM), Universidade Federal de São Carlos (UFSCAR), Universidade Federal do Espírito Santo (UFES), Universidade Federal do Rio de Janeiro (UFRJ), Universidade Federal do Rio Grande do Norte (UFRN), Universidade Federal do Rio Grande do Sul (UFRGS), Universidade Federal do Vale do São Francisco (UNIVASF), Universidade Metodista de Piracicaba (UNIMEP), UNIVERSO e Universidade São Judas Tadeu (USJT).

${ }^{5} \mathrm{O}$ ano de 2004 data o início do banco de dados online disponibilizado pelo periódico. 
${ }^{6}$ Plataforma desenvolvida pela Capes, entre suas ferramentas, possibilita identificar os Programas de PósGraduação no Brasil. Disponível em: https://sucupira.capes.gov.br. Acesso em: 11 jun. 2018.

${ }^{7}$ Barra de São Francisco, Boa Esperança, Pinheiros, São Gabriel da Palha e São Mateus.

${ }^{8}$ Dispõe sobre o processo eleitoral para escolha dos diretores das escolas públicas do município.

Enviado em: 28/09/2019

Aprovado em: 30/12/2019 